\title{
Os reflexos da pandemia da COVID-19 na profissão Músico em Manaus-Amazonas: decreto estadual, trabalho, saúde e emocional
}

\author{
Lucyanne de Melo Afonso ${ }^{1}$ \\ Universidade Federal do Amazonas \\ lucyanneafonso@ufam.edu.br
}

Resumo: A pesquisa apresenta os reflexos da pandemia da COVID-19 na vida do músico em Manaus relacionados a saúde, trabalho e emocional durante o período de fechamento dos bares e restaurantes pelo Decreto Estadual $\mathrm{n}^{\circ} 42330$ de 28 de maio de 2020, conforme as orientações da Organização Mundial de Saúde. Utilizou uma abordagem metodológica mista quantitativa e qualitativa, cujos dados foram obtidos através de um formulário online, sem identificação de nome e e-mail para preservar a identidade do entrevistado. O questionário abordava perguntas sobre o cotidiano do músico antes da pandemia e durante a pandemia e o decreto instituído. A pesquisa nos possibilitou conhecer esse novo cotidiano e cenário da vida do músico: preocupações e ansiedades, dificuldades financeiras, desvalorização dos profissionais, além de problemas emocionais que geraram conflitos internos. Registrar a memória desses sujeitos sociais é valorar e dar voz aos atores que fizeram parte de um cenário musical local, em um momento de pandemia mundial.

Palavras-chave: Pandemia da COVID-19, Decreto Estadual nº42330 de 28/05/2020, Profissão Músico, ManausAmazonas.

\section{The reflexes of the pandemic COVID-19 in the profession Musician in Manaus-Amazonas: state decree, work, health and emotional}

Abstract: The research presents the reflexes of the COVID-19 pandemic in the life of the musician in Manaus
related to his health, work, and emotional health during the period of closure of bars and restaurants by State
Decree No. 4230 of May 28, 2020, according to the guidelines of the World Health Organization. Health. Using a
mixed quantitative and qualitative methodological approach, data were obtained through an online form, without
name and e-mail identification to preserve the interviewee's identity. The questionnaire addressed questions about
the musician's daily life before the pandemic and during the pandemic and the instituted decree. The research
allowed us to get to know this new daily life and scenario of the musician's life: concerns and anxieties, financial
difficulties, devaluation of professionals, in addition to emotional problems that generated internal conflicts. To
record this memory of these social subjects is to value and give voice to the actors who were part of a local music
scene in a time of global pandemic.
Keywords: Pandemic COVID-19, State Decree No. 4230 of $05 / 28 / 2020$, Profession Musician, Manaus-Amazonas.

\section{Introdução: Música, pandemia e decreto estadual}

Em cada época da humanidade, a música exerce diferentes funções: seja para divertir, para acalentar, para inspirar, para articular as variadas expressões culturais ou mesmo para representar um fato histórico. O músico é um dos agentes dessa articulação da música com a sociedade, em que vivencia e movimenta a vida cotidiana conforme os paradigmas de seu tempo, suas ideologias e paixões.

A vida cotidiana é a vida do homem inteiro; ou seja, o homem participa na vida cotidiana com todos os aspectos de sua individualidade, de sua personalidade.

\footnotetext{
${ }^{1}$ Grupo de Estudo e Pesquisa em Música na Amazônia; Laboratório de Musicologia e Educação Musical da Faculdade de Ares - UFAM.
} 
Nela, colocam-se "em funcionamento" todos os seus sentidos, todas as suas capacidades intelectuais, suas habilidades manipulativas, seus sentimentos, paixões, ideias, ideologias (HELLER, 2016, p.35).

O cotidiano do músico na época atual é bastante intenso: uma vida social com alegrias, histórias, mas também com muito estresse. Viver de música exige estudo, dedicação, compromisso e disponibilidade; são horas de ensaio, estúdio e gravações; apresentações em diferentes ambientes; é necessário ter equipamentos de qualidade, investimento na divulgação do trabalho, na imagem e na carreira profissional, tudo isso para que o público, em diferentes ambientes artísticos, tenha satisfação e gosto pela sua música e pela sua arte.

A profissão, apesar de passar uma imagem de fascinação, encantamento e admiração para quem assiste ou se diverte, ainda possui desvalorização profissional, preconceito com quem vive de música e mais incentivo às políticas culturais do que fomenta o setor cultural. O músico autônomo não tem estabilidade financeira, o seu sustento vem dos shows em estabelecimentos de entretenimento e espaços culturais. Após a pandemia, tudo mudou: rotinas, formatos, situações.

No início da pandemia em Manaus, em meados do mês de março de 2020, quando começaram a surgir os primeiros casos da COVID-19, algumas instituições iniciaram o isolamento (como as universidades federais e as escolas das redes municipal, estadual e privada) e a perspectiva daquele momento era de que o estado pandêmico passaria logo, mas a situação se agravou rapidamente e os números de contaminados e mortos aumentavam a cada dia. Isso assustou a todos.

O cenário musical local sofreu alterações, após o início do isolamento, mas mesmo assim muitos bares e restaurantes continuaram com as atividades normalmente: da periferia aos restaurantes sofisticados. As bandas e os músicos também se faziam presentes nestes ambientes, não por divertimento, mas pela necessidade financeira mensal/semanal, pois são desses shows em estabelecimentos que a maioria dos músicos da noite sustenta suas famílias. Mas o que não esperávamos era uma piora no número de casos.

Considerando a grave crise de saúde pública, em decorrência da pandemia da COVID19, declarada pela Organização Mundial da Saúde (OMS) (2021a), o Governo do Estado do Amazonas promulgou o Decreto Estadual no 42.330 (AMAZONAS, 2020a), e, conforme em seu artigo $1^{\circ}$ inciso VI, proibiu "o funcionamento de todas as boates, casas de shows, bares, casas de eventos e de recepções, salões de festas, inclusive privados, parques de diversão, circos e estabelecimentos similares", paralisando as atividades musicais. 
Uma vez que todos os shows, com toda a razão, foram suspensos para auxiliar no controle da pandemia do COVID-19, de onde virá o sustento desses músicos que estão por aí sendo intimados a disponibilizarem seu trabalho como se fossem voluntários em uma espécie de Músicos Sem Fronteiras? O atual desamparo ao qual a classe artística musical está submetida só expõe a fragilidade, a precariedade e a vulnerabilidade do trabalho musical no Brasil nos últimos anos (GONÇALVES, 2020).

O decreto fechou estabelecimentos e espaços culturais em que o músico atuava para ter sua renda: muitos casamentos, confraternizações e festas em Manaus foram cancelados; bares, shoppings, restaurantes, cafés e espaços culturais pararam e, consequentemente, diferentes situações pessoais e cotidianas emergiram e se agravaram.

Toda esta situação perdurou por um período de quatro meses (junho, julho, agosto, setembro de 2020). A flexibilização iniciou a partir do mês de outubro de 2020, mesmo assim, com muitas restrições. Quatro meses sem trabalho, sem renda e sem espaço levaram muitos músicos a enfrentar situações de fragilidade financeira e emocional difíceis.

Quem paga a conta dos músicos? Aplausos, visualizações e curtidas virtuais, via de regra, não enchem os bolsos do artista nem de toda a cadeia produtiva que está por trás de uma canção gravada, composta ou apresentada (destaquemos aqui a extensa rede de produtores, instrumentistas, compositores, técnicos de som etc.) (GONÇALVES, 2020).

É uma das profissões em que o produto é valorizado, mas quem o realiza é desvalorizado, muitas vezes com palavras pejorativas carregadas de memória histórica da representação da vida de músico pelas sociedades em diferentes tempos.

Mas a memória coletiva é não somente uma conquista, é também um instrumento e um objeto de poder. São as sociedades cuja memória social é, sobretudo, oral, ou que estão em vias de constituir uma memória coletiva escrita, aquelas que melhor permitem compreender esta luta pela dominação da recordação e da tradição, esta manifestação da memória (LE GOFF, 2013, p.435).

A memória e as lembranças se presentificam nas falas e nas histórias carregadas de emoção, sentimentos e saudades. Le Goff (2013) salienta que a memória, dentro dessas áreas científicas, pode evocar de forma metafórica ou concreta a memória histórica e a memória social das sociedades com seus traços e seus problemas.

A memória está muito relacionada com o modo como cada sociedade se organiza e fundamenta seus princípios filosóficos, históricos e socioculturais. Segundo Fubini (2003), a memória musical é a memória da historicidade social e cultural de uma dada sociedade.

Contudo, não devemos concluir que a música é um eterno presente, em que tudo é possível, em que tudo é permitido. Trata-se ao invés, de reconhecer que a música implica um modelo diferente de historicidade, de consciência da sua historicidade e, consequentemente, de memória histórica (FUBINI, 2003, p. 44). 
Em tempos de pandemia, a música sustentou a base emocional, afetiva e transmitiu empatia a muitas pessoas. A música provoca sensações e é o que o público busca quando vai assistir a um show ou espetáculo, ou quando se torna fã de um artista: buscamos uma identificação com os nossos sentimentos e que influencie nossa vida.

A União Brasileira de Compositores realizou uma pesquisa entre músicos, compositores, intérpretes e outros profissionais da música e averiguou como a pandemia afetou o mercado musical.

As carreiras mais prejudicadas pela pandemia foram as de instrumentistas (49\%), intérpretes (49\%) e compositores $(35 \%)$, seguidas por produtores fonográficos (25\%) e, em menor medida, arranjadores, professores de música, empresários, empregados de editoras e selos e roadies (SILVA, 2020, grifo nosso).

Esta porcentagem retrata muito o que ocorreu na realidade de músicos que atuavam no setor de bares e restaurantes em Manaus e mostra que foram os mais prejudicados com a falta de trabalho e, consequentemente, com o surgimento de outros problemas de ordem financeira e emocional.

\begin{abstract}
Todos querem consumir música, mas nem todos querem remunerar os músicos. E isso não é de hoje: vem desde o consumo musical fácil, rápido e gratuito através das plataformas digitais. O que vemos agora, em um momento de fragilidade financeira de músicos, que dependem de seus shows presenciais para tirar seu sustento, é só a gota d'água de um processo que vem se acumulando há anos (GONÇALVES, 2020).
\end{abstract}

O músico teve que se recriar, "foi necessário aquisição de novos equipamentos de captação de áudio e vídeo, além da necessidade de desenvolvimento, em tempo recorde, de habilidades para edição de vídeos/áudios, postagens e engajamento nas redes sociais" (LOURO, LOURO e DUARTE, 2020, p.382). Aqueles que tinham mais condições financeiras e apoio empresarial tiveram mais estrutura de usufruir dessa tecnologia, enquanto outros tiveram que buscar alternativas fora do ambiente musical.

Louro, Louro e Duarte (2020) relatam que além das demandas comuns que todo músico passa na profissão como excesso de estudo, instabilidade do mercado, competitividade, ansiedade e entre outros, com a pandemia novas demandas surgiram e/ou dificultaram ainda mais o exercício da profissão, como: as perdas de emprego em decorrência do fechamento de espaços, adaptação na realização de lives e uso de outros equipamentos, solidão, medo de adquirir a doença e falta de incentivos públicos para ajudar na manutenção mensal. 
Em decorrência do Amazonas ter sido uma das primeiras capitais a ser infectada gravemente com a doença COVID-19, o reflexo da pandemia no circuito musical foi um dos primeiros do Brasil a sofrer drasticamente com o isolamento e a paralisação das atividades.

O objetivo da pesquisa foi investigar as condições emocionais, financeiras, sociais e de saúde dos músicos em Manaus em função da pandemia da COVID-19 durante o período de fechamento dos bares e restaurantes pelo Decreto Estadual nº42.330 de 28 de maio de 2020 e das orientações da Organização Mundial de Saúde (AMAZONAS, 2020a; WORLD HEALTH ORGANIZATION, 2020b).

Vamos apresentar o reflexo da pandemia através de depoimentos, memórias e relatos de músicos que atuam em diferentes espaços do circuito musical em Manaus. Conhecer este outro lado é importante para traçarmos os fatos reais e compreender as dinâmicas sociais e culturais que ocorreram neste período do Decreto Estadual em um contexto de pandemia mundial, além de proporcionar outros estudos e pesquisas que possam contribuir para agregar conhecimento desse grupo sociocultural e dar parâmetros para novas conquistas coletivas.

\section{Método}

Esta pesquisa teve como suporte a abordagem metodológica mista: quantitativa, para buscar "a construção de variáveis que permitam a mensuração ou a quantificação dos fenômenos sociais", e qualitativa, para "entender os significados subjetivos atribuídos pelas pessoas pesquisadas aos seus contextos e suas realidades [...]" (CASA NOVA, 2020, p.83). Utilizou-se também o método de questionário semiestruturado, para conhecer as histórias de vida e registrar a memória de um tempo no cenário musical em Manaus. Segundo Freire (2007, p. 32) "as informações obtidas podem dar origem a tratamento estatístico [...]. Podem também servir de material primário para interpretação de pesquisa, sem necessidade de quantificação (pesquisas qualitativas)".

Para registrar essa memória da música em Manaus, de um tempo e de uma sociedade, foi aplicado um questionário através do Formulário Google para coletar os dados: sem a indicação de nome e e-mail, contendo termo de consentimento e aceite para participar de forma voluntária e sem ônus. $\mathrm{O}$ formulário ficou disponível no período de 16 de novembro a 10 de dezembro de 2020. O grupo de interesse para a aplicação do questionário foi de músicos que atuavam em bares, restaurantes, espaços culturais e eventos sociais, como festas de casamento e aniversários. 
O questionário foi dividido em duas seções, totalizando 30 perguntas relacionadas aos aspectos financeiro, social, emocional e de saúde do músico:

- Sessão 1 - Conhecendo o cotidiano antes da pandemia. Nesta seção foram 8 perguntas de múltipla escolha e 4 perguntas abertas. Estavam direcionadas para as áreas de trabalho do músico, a quantidade de grupos musicais que fazia parte e os gêneros musicais que tocava, outros trabalhos que exercia, a rotina semanal e os lucros mensais; como era sua saúde mental e os estados emocionais em função do trabalho.

- Sessão 2 - Conhecendo o cotidiano durante a pandemia, com o Decreto Estadual. Nesta seção foram 10 perguntas de múltipla escolha e 8 perguntas abertas. Estavam direcionadas à alteração de rotina e o que realizara como músico; às questões financeiras: se a renda diminuiu e realizou outra atividade para ter renda ou conseguiu auxílio do Governo; à saúde mental: como ela foi afetada diante dos problemas e da pandemia ou se já fazia tratamento como parte da rotina, anteriormente; se a tecnologia ajudou nesse momento com a sua profissão ou exerceu outra atividade. As demais perguntas estavam relacionadas à COVID-19: se pegou o vírus ou conheceu colegas de profissão que pegaram ou que faleceram e como lidou com esta situação.

$\mathrm{O}$ formulário foi encaminhado aos músicos que pertencem a grupos de redes sociais e compartilhados pelos mesmos. A estimativa era receber mais de 40 respostas pelo fluxo e velocidade das redes sociais no momento da pandemia. Alguns esqueceram e outros se abstiveram de responder. No entanto, o formulário recebeu 17 respostas, um quantitativo razoável que representa as diferentes situações vividas e os diferentes sujeitos sociais e seus grupos culturais da música local: de bandas de rock, pop, forró, a instrumentistas de orquestra e grupos musicais que atuam em eventos.

Registrar a memória desses sujeitos sociais é valorar e dar voz aos atores que fizeram parte de um cenário musical local em um momento de pandemia mundial: como os músicos se reinventaram, o que mudou, que dificuldades e problemas financeiros enfrentaram e, principalmente, as questões de ordem emocional e de saúde que emergiram durante o decreto.

\subsection{Resultados e Discussão}

\subsubsection{O cotidiano do músico em Manaus antes da pandemia}

O cotidiano do músico em Manaus é dinâmico, festivo e alegre pela própria natureza do trabalho. Trabalhar com música é um privilégio de poder levar momentos de alegria, descontração e recordações às pessoas, uma rotina dura e doce ao mesmo tempo: pela 
instabilidade financeira, pelo desrespeito à categoria em diferentes frentes seja social, cultural ou em políticas culturais.

O perfil do músico é bem eclético, atua em diferentes tipos de espaços: bares e restaurantes, espaços culturais (teatros, museus, cinema etc.), e variados eventos sociais como casamentos, aniversários, bailes, etc.

Figura 1: Tipos de espaços do trabalho do músico em Manaus.

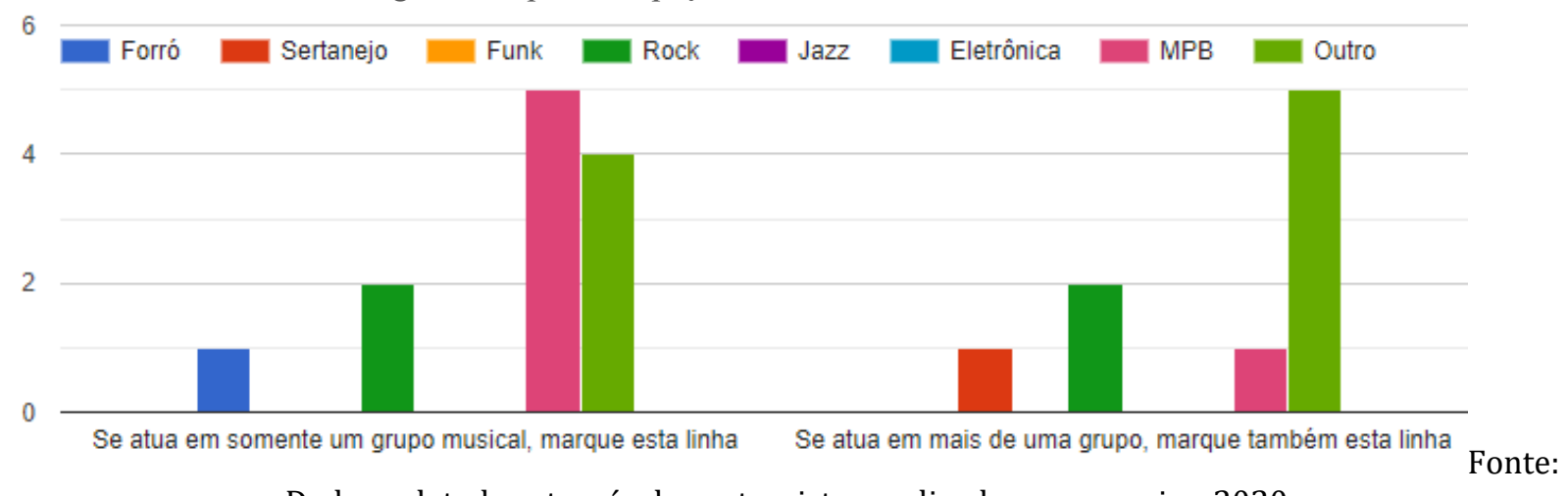

Dados coletados através das entrevistas realizadas na pesquisa, 2020.

Este dinamismo tem relação com os $64,7 \%$ que responderam a pesquisa e que atuam em mais de um grupo musical (Figura 1), levando-nos a compreender a diversidade de estilos musicais que atuavam antes da pandemia: 1) 35,3\% participam de um grupo musical: MPB, rock, erudito; 2) 64,7\% participam de mais de um grupo musical, sendo a) Grupo principal: MPB, Rock e Forró; e b) Grupos Secundários: Pop, Instrumental, Orquestra, shows alternativos, Música regional, Religioso, Coro Lírico, música erudita, Rock, MPB, Locadora de sonorização.

Conforme podemos perceber na Figura 1, a rotina do músico é intensa, com muito trabalho e ensaios em diferentes ambientes sociais e culturais, um cotidiano de alegria, raiva, tristeza, estresse e medo.

De quarta a domingo, extrema correria com a agenda de shows. Segunda-feira dia da folga, terça de ensaios ou planejamentos. No nosso formato requer um pouco mais de tempo e dedicação, nenhum dos integrantes trabalha com segunda opção, então, para cumprir uma agenda de shows já nos preparamos horas depois, sempre passando som antes do horário do público chegar. Os finais de semana tendem a ser mais intensos, devido ao cumprimento de agendas na parte da manhã e noite. (Participante 1)

Participava de ensaios de 3 a 4 dias durante a semana. (Participante 2)

Geralmente ensaio uma vez na semana e faço shows nos finais de semana. (Participante 3)

Trabalhava nos fins de semana fazendo shows, voz e violão. (Participante 12)

Apenas faculdade e vez ou outra alguma apresentação. (Participante 16) 
Apresentações musicais todas as sextas e sábados. (Participante 17).

Quanto a ter uma outra profissão paralela, 41,2\% não possuem e 58,8\% têm outra profissão principal, ajudando na somatória da renda mensal.

Figura 2: Renda mensal

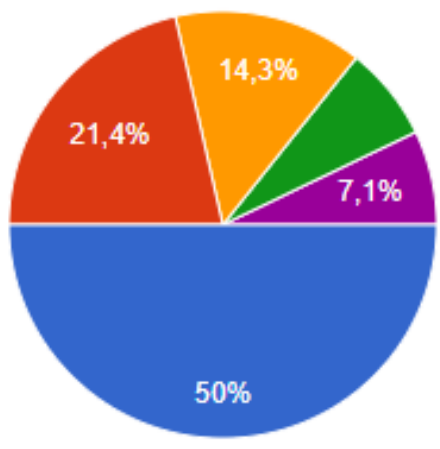

Entre $R \$ 500,00$ a $R \$ 2.000,00$

$R \$ 2.000,00$ a $R \$ 4.000,00$

$R \$ 4.000,00$ a $R \$ 6.000,00$

$R \$ 6.000,00$ a $R \$ 8.000,00$

Mais de $\mathrm{R} \$ 8.000,00$

Fonte: Dados coletados através das entrevistas realizadas na pesquisa, $2020 .^{2}$

A média de renda mensal dos músicos que não tinham outra profissão e atuavam somente em um grupo musical variava entre $R \$ 500,00$ e $R \$ 2.000,00$, perfazendo entre 2 e 5 shows mensais, ou um lucro acima de $\mathrm{R} \$ 8.000,00$, com 27 apresentações mensais; os músicos que atuavam em um grupo musical e tinham outra profissão, a média de renda mensal era de $\mathrm{R} \$$ 2.000,00 a $\mathrm{R} \$ 6.000,00$; os músicos que atuavam em mais de um grupo musical e não tinham outra profissão geravam em torno de $\mathrm{R} \$ 2.000,00$ a $\mathrm{R} \$ 8.000,00$, com média de 10 a 25 shows por mês; e os músicos que atuavam em mais de um grupo musical e tinham outra profissão perfaziam uma renda mensal entre $\mathrm{R} \$ 2.000,00$ e mais de $\mathrm{R} \$ 8.000,00$, com uma média de 6 a 15 shows mensais.

Mesmo os músicos atuando em mais de um grupo e/ou com outro trabalho paralelo, $57 \%$ tinham dificuldades financeiras ao final do mês: gastos com a manutenção e/ou compra de equipamentos, despesas fixas (aluguel, água, luz, internet), cuidados com a saúde, gastos pessoais, sociais e culturais, entre outros. Nem sempre o valor que recebiam comportava as necessidades individuais e familiares.

Às vezes não tinha como comparecer nos ensaios por não ter dinheiro pra por gasolina, ou sequer pegar ônibus ou almoçar fora quando os ensaios eram seguidos, então, ficava com fome. (Participante 2)

Transporte e despesas de casa. (Participante 6)

Alimentação, transporte e manutenção do instrumento. (Participante 10)

Deixava de pagar algumas contas. (Participante 13)

\footnotetext{
${ }^{2}$ Porcentagem referente a $\mathrm{R} \$ 6.000,00$ a $\mathrm{R} \$ 8.000,00$ (cor verde) foi de 7,1\%.
} 
Diante das adversidades e dificuldades, $82,4 \%$ não faziam nenhum tratamento de doença mental, sendo que a ansiedade e a depressão são citadas pelos músicos com renda financeira menor. É importante salientar que este indicativo corresponde a sentimentos que são necessários investigar para uma melhor qualidade de vida no trabalho: depressão, medo, ansiedade e estresse.

O dia a dia "normal” já era preocupante. Após o Decreto Estadual n42.330, este cenário mudou de uma situação mensal preocupante para uma situação caótica, sem saber o dia da volta ao trabalho e tendo que enfrentar dilemas entre saúde $\mathrm{X}$ dinheiro, sobrevivência $\mathrm{X}$ entretenimento, emocional X saudades, vida X mortes (AMAZONAS, 2020a).

\subsubsection{O cotidiano do músico em Manaus durante o Decreto Estadual no contexto de crise sanitária - pandemia da COVID-19}

O Decreto Estadual n 42.330 de 28 de maio de 2020 foi homologado pelo Governador do Amazonas, Wilson Lima, para frear a transmissão da COVID-19, em Manaus (AMAZONAS, 2020a).

Os meses de abril e maio de 2020 foram os com maior pico de transmissão do vírus, hospitalizações e mortes, chegando a ter, no dia 27 de maio, 39 óbitos $^{3}$. Esse número cada vez aumentava e eram necessárias medidas de enfrentamento da emergência da saúde pública de importância internacional, conforme os dados abaixo apresentados pela Fundação de Vigilância em Saúde - FVS/AM.

\footnotetext{
${ }^{3}$ CASOS de COVID-19 no AM sobem para 33.508 e mortes chegam a 1.891. 27 maio 2020. Disponível em: https:/g1.globo.com/am/amazonas/noticia/2020/05/27/casos-de-COVID-19-no-am-sobem-para-33508-e-morteschegam-a-1891.ghtml. Acesso em: 10 dez. 2020.
} 
Figura 3: Gráfico de evolução da COVID-19 nos meses de abril a junho de 2020, em Manaus.

\section{Casos novos de Covid-19 por semana no Amazonas}

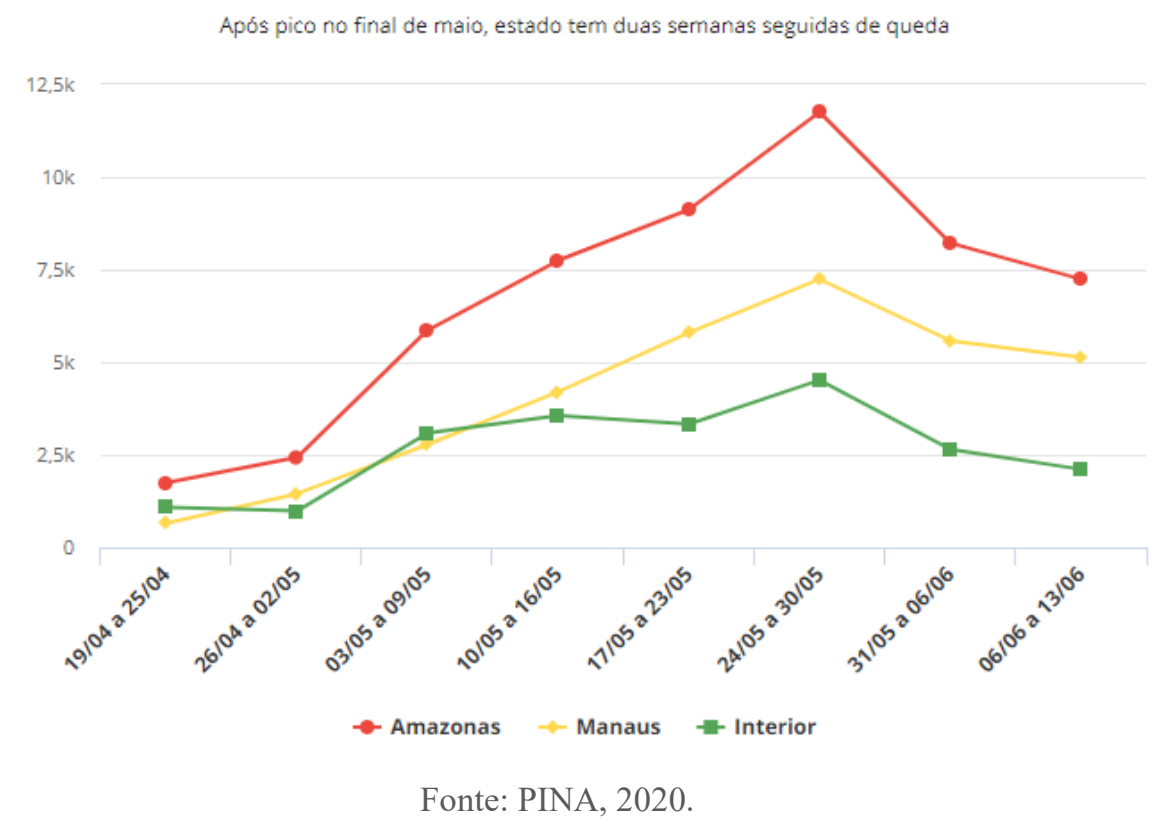

Entre as medidas de enfrentamento, estavam a suspensão das seguintes atividades, conforme o Artigo $1^{\mathrm{o}}$ :

Aulas, no âmbito da rede pública estadual de ensino, integrada pela Secretaria de Estado de Educação e Desporto, bem como pelo Centro de Educação Tecnológica do Amazonas, pela Universidade do Estado do Amazonas e pela Fundação Aberta da Terceira Idade; a visitação a presídios e a centros de detenção para menores; o serviço de transporte fluvial de passageiros; a visitação a pacientes internados com COVID-19; o funcionamento de todas as boates, casas de shows, bares, casas de eventos e de recepções, salões de festas, inclusive privados, parques de diversão, circos e estabelecimentos similares; o recadastramento dos servidores ativos e inativos; a realização de eventos, promovidos pelo Governo do Estado do Amazonas, de quaisquer natureza, incluída a programação dos equipamentos culturais públicos (AMAZONAS, 2020a).

Este Decreto paralisou Manaus em muitos sentidos, da vida ribeirinha e rural à vida urbana: o transporte fluvial foi bloqueado, pois a transmissão do vírus já estava em muitos municípios do Amazonas, inclusive em São Gabriel da Cachoeira ${ }^{4}$, deixando muitas pessoas sem poder retornar as suas casas; shoppings, centros comerciais, bares, restaurantes, flutuantes ${ }^{5}$, parques e teatros, todos fechados.

Os empregos e os subempregos deram lugar à vida, a princípio, mas em um sistema capitalista e com divisão de classes a condição e a realidade são diferenciadas. "Estou sem

\footnotetext{
${ }^{4}$ Município com maior número de etnias indígenas.

${ }^{5}$ São restaurantes ou bares que ficam no rio, servem comida regional, bebidas e a diversão com mergulho na água. Pode ter acesso via estrada ou por via fluvial.
} 
esperanças. Infelizmente, as dívidas não pararam e as coisas aumentaram" (Participante 3). Em torno de todo este dilema, entre viver e trabalhar para viver, encontravam-se os músicos.

Assim para chegar até as sensibilidades de um outro tempo, é preciso que elas tenham deixado um rastro, que cheguem até o presente como um registro escrito, falado, imagético ou material, [...]. Mesmo um sentimento, uma fantasia, uma emoção, precisam deixar pegadas. (PESAVENTO, 2008, p; 46)

Parafraseando Certeau (1994), as experiências do tempo vivido são formadas pelos passos construídos em diferentes espaços, cada tempo presente torna-se um tempo do passado que vai constituindo trajetórias individuais e coletivas que são frutos de mecanismos sociais.

Toda trajetória social deve ser compreendida como uma maneira singular de percorrer o espaço social, onde se exprimem as disposições do habitus; cada deslocamento para uma nova posição, enquanto implica a exclusão de um conjunto mais ou menos vasto de posições substituíveis e, com isso, um fechamento irreversível do leque dos possíveis substituíveis. (BOURDIEU, 1996, p.292)

Com o Decreto Estadual, todo o habitus foi alterado e nessa alteração ficou mais evidente as diferenças no próprio campo das necessidades e situações vivenciadas: um novo fazer para novas práticas sociais e culturais e legitimação no mercado e no cotidiano musical. No início, muitos músicos se ocuparam com estudos, composições e arranjos para passar o tempo durante o Decreto e a pandemia.

\footnotetext{
Melhoramos o repertório com a ajuda do público das lives. Eles faziam pedidos e o que encaixa no nosso conceito a gente acatava. (Participante 1)

Apenas estudando, teoria musical, percepção, fazendo cursos, participando de festivais online, simpósios, etc. (Participante 2)

Estudos e algumas gravações a distância com alguns grupos/bandas. (Participante 6)

Compondo e escrevendo projetos. (Participante 12)

Estúdio de gravação. (Participante 13)
}

Mas o tempo de uma pandemia e de um vírus não é igual ao tempo da música ou o tempo da necessidade financeira. As necessidades foram surgindo, novas técnicas e ferramentas tiveram que ser aprendidas, conforme o cenário da pandemia se modificava. Para isso, o músico teve que se reinventar, agregar as novas tecnologias em seu cotidiano, se apresentar em um novo palco e com novas formas de interagir com o público.

As tecnologias e as ferramentas digitais para a produção da música já estão presentes desde a revolução industrial, "as grandes mudanças iniciadas pela revolução industrial alcançaram os lares dos cidadãos comuns, que substituíram seus instrumentos musicais por máquinas feitas para reproduzir música gravada" (GOHN, 2017, p.23). A sociedade modifica 
suas práticas conforme as novas técnicas e ferramentas disponíveis, é um processo irreversível, pois a sociedade é dinâmica.

Sistemas permitem que máquinas separadas por grandes distâncias possam enviar entre si músicas digitalizadas, indivíduos disponibilizam seus discos para outros indivíduos que jamais irão conhecer pessoalmente, obras são adquiridas virtualmente e baixadas pela internet (GOHN, 2011, p. 24).

A aprendizagem para a manipulação de outras ferramentas digitais foi essencial para se conectar com o público e manter o equilíbrio financeiro e emocional. A tecnologia foi a grande aliada nesse novo fazer: shows presenciais se transformaram em shows virtuais, os palcos deram lugar às lives e às videoconferências.

Colaborou $100 \%$, foi nossa principal forma de se comunicar com o público e ter uma ajuda, não só financeira, mas também, de estado de espírito! (Participante 15)

Pude participar de muitos encontros virtuais, que se fossem presenciais não poderia participar, pois seriam em outros estados. (Participante 2)

Algo que mudou totalmente nossa rotina e que abalou muito a nossa saúde física e mental. Ao mesmo tempo, percebemos a importância da tecnologia em nossa profissão e que devemos aprender novas ferramentas caso queiramos continuar com nosso trabalho. (Participante 5)

No período da permanência do Decreto, principalmente entre os meses de junho e setembro de 2020, 37,5\% dos músicos realizaram apresentações e shows e 18,8\% esporadicamente realizavam. Entre as principais atividades realizadas, temos lives, som ao vivo em restaurantes, apresentação com a Orquestra, cultos, novenas, casamentos e apresentações em videoconferências.

Sim, através do couvert digital deixávamos o público das lives para contribuir com qualquer valor. Dono de supermercado que tinha palco isolado nos proporcionou algumas apresentações durante o fechamento das casas noturnas. Empresários admiradores do nosso trabalho também contribuíram bastante. (Participante 1)

Sendo que 43,8\% não realizaram nenhuma apresentação, esse quantitativo representa como a maioria dos músicos ficou nesse período. Praticamente, eram os que realizavam entre 4 e 6 shows por mês, com um lucro mensal de $\mathrm{R} \$ 500,00$ a $\mathrm{R} \$ 2.000,00$.

Músicos contratados pelo Estado estão mantendo os seus empregos. Quanto aos músicos autônomos, aí sim houve redução considerada de cachês, devido ao fechamento dos bares e restaurantes. (Participante 8)

Pelo fato de ser um trabalho autônomo, tive muita dificuldade em ter renda e fazer o que gosto. Não ter uma estabilidade complica. (Participante 12)

Estas questões de investir para poder atuar na cena musical por meio virtual impactaram também na renda mensal: a compra de novos equipamentos para gravação de lives geraria custos extras que poderiam interferir em necessidades essenciais. A figura abaixo apresenta 
como as questões financeiras foram alteradas, impactando no cotidiano profissional e pessoal: $18,8 \%$ (azul) não tiveram alteração na renda mensal; 37,5\% (vermelho) tiveram totalmente alteração na renda; $18,8 \%$ (amarelo) tiveram alteração parcial na renda mensal; e 25\% (verde) tiveram pouca alteração, em função de terem outra atividade.

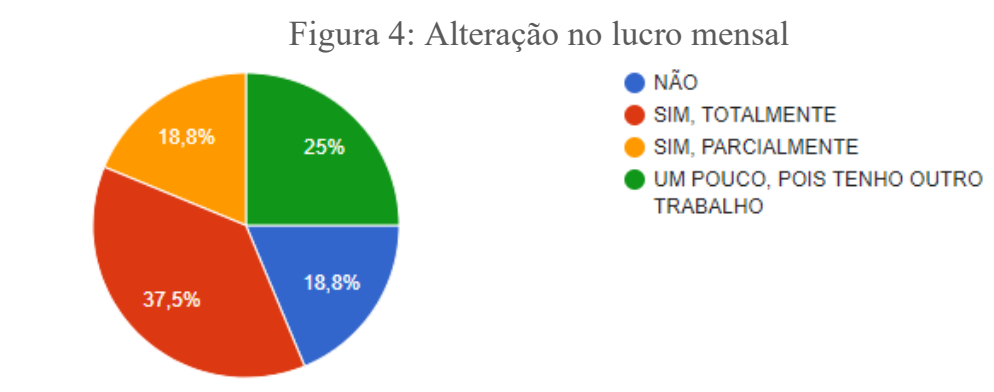

Fonte: Dados coletados através das entrevistas realizadas na pesquisa, 2020.

É evidente que quem não teve perdas financeiras tinha outro trabalho e obtinha uma renda a partir de R \$ 4.000,00 por mês, não possuindo tantas dificuldades. Os demais músicos tiveram que se reinventar, ou seja, buscar outras formas de suprir as necessidades diárias e mensais. Cada um buscou, da sua forma, outras alternativas de fonte de renda: motorista de aplicativo, serviços elétricos, comércio, aulas, auxílio emergencial do Governo Federal (MEI = Microempreendedor Individual), caixa de mercadinho, entre outras atividades que ajudaram a manter as despesas do mês.

Essa reinvenção levou também a se questionarem se valeria a pena retornar à profissão, principalmente os autônomos. Um músico, pai ou mãe de família, que vive da música e não tem outra atividade, permanecendo somente com o trabalho da música, não teria o suficiente para a estabilidade e subsistência familiar, afetando emocionalmente os participantes nestas condições, em especial os que tinham a renda mensal de $\mathrm{R} \$ 500,00$ a $\mathrm{R} \$ 2.000,00$ que relataram ansiedade, depressão e síndrome do pânico. 
Figura 5: Desenvolvimento de doença psíquica no período do Decreto

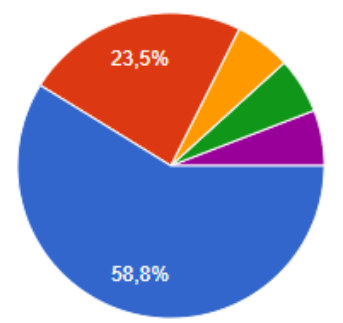

- NÃO

ANSIEDADE

DEPRESSÃO

SÍNDROME DO PÂNICO

- JÁ TINHA/FAZIA TRATAMENTO

OUTRA

Fonte: Dados coletados através das entrevistas realizadas na pesquisa, 2020 6 ; 7;8

Apesar de 58,8\% não terem desenvolvido nenhum tipo de doença mental, não significa que não tiveram problemas, estresse e preocupações. Alguns depoimentos expressam as sensações que passaram:

No dia seguinte, nossa agenda foi cancelada como um efeito dominó, foi uma das piores sensações. Tivemos todos os shows cancelados de uma vez. O último show que fizemos antes dessa situação deixou muita saudade! (Participante 1)

Estresse. Pois o mês passa e às vezes não sabia se teria o dinheiro necessário para pagar as contas no fim dele, ou fazer um rancho, etc. (Participante 2)

Extremamente abalado. Nunca fui acostumada a ficar em casa e tive que ficar por meses, foi extremamente agonizante essa mudança radical. (Participante 10)

Me sinto doente e estressada. (Participante 13)

Estou normal, pois não fiquei completamente sem renda, mas diminuiu em $50 \%$ +ou-. (Participante 15)

Péssima, sem motivação para estudar música, já que não tem onde trabalhar, por enquanto. (Participante 16)

Além desses fatores, um outro medo rondava: o medo de estar com COVID-19. Do grupo entrevistado, 75\% não contraíram COVID-19, 76,6\% conheceram algum músico que foi infectado. Além disso, 35,7\% tiveram conhecimento que entre 11 e 20 músicos conhecidos pegaram COVID-19, 93,8\% responderam que conheceu ou soube de algum músico que morreu por COVID-19, sendo de 2 até 7 o número de músicos conhecidos que faleceram.

Não peguei COVID durante a quarentena, pra mim foi bem recente. Mesmo que eu não tenha desenvolvido problemas psicológicos durante o isolamento, também chegou minha vez de sentir coisas que ainda não tinha sentido, pois nesse momento estamos praticamente vivendo uma segunda onda de COVID, praticamente todos que conheço estão pegando, alguns se internando. Depois que peguei (mesmo com sintomas leves), passei a sentir extrema angústia e tristeza, nem a minha rotina de show estava me revigorando, passei a sentir dor muscular de me sentir tensa, tive que procurar espairecer o dia inteiro e orar muito pra Deus me deixar leve e tirar a tristeza do meu coração, de ver tanta coisa ruim acontecendo. Nós músicos temos as emoções muito afloradas, nesses tempos

\footnotetext{
${ }^{6}$ Porcentagem referente a Depressão (cor amarelo) foi de 5,9\%.

${ }^{7}$ Porcentagem referente a Síndrome do pânico (cor verde) foi de 5,9\%.

${ }^{8}$ Porcentagem referente a se o participante já tinha/fazia tratamento (cor lilás) foi de 5,9\%.
} 
quando termino show, gosto de desejar saúde para todo o público que me assistiu, um desejo que tudo volte ao normal, um desejo que as pessoas superem isso. (Participante 1)

Muitos foram os casos de COVID na categoria dos músicos em Manaus: as mortes e/ou o agravamento da doença abalaram emocionalmente colegas de profissão. A seguir, é possível ver alguns depoimentos que retratam cenas e experiências vivificadas por músicos nesse período do Decreto Estadual como medida de enfrentamento da COVID-19 em Manaus e que ficarão na memória individual e coletiva e nos registros desse texto para futuras pesquisas e compreensão dos fatos.

\begin{abstract}
Nem todos os músicos conseguiram se manter durante esse período tão difícil. Eu agradeço a Deus por, de certa forma, ter tido a prova do quanto o meu trabalho tem sido importante para o bem-estar de tantas pessoas, pois foram essas pessoas que valorizaram a música quando ela mais precisou. Valorizando a música também se valoriza o músico que vive dela. Foi difícil e está sendo difícil passar por isso, mas seguimos firmes! (Participante 1)
\end{abstract}

O mundo já era difícil pra quem vivia só da música. A pandemia piorou muito mais as coisas. E por mais que as pessoas tenham sentido "falta" de show e entretenimento em geral, a desvalorização da profissão ainda é grande. (Participante 6)

Não sei nem o que dizer. É uma situação totalmente atípica e muito cruel. Estamos sem assistência e sem esperança. (Participante 13)

Tenho visto muita solidariedade entre os músicos. Assisti a diversas lives beneficentes em prol de outros músicos e também de outras pessoas. (Participante 14)

Uma situação lamentável para alguns colegas que tiveram que parar 100\% suas atividades por serem pessoas de risco para a COVID-19. Por outro lado, vários colegas continuaram trabalhando durante a pandemia. (Eu mesmo toquei com colegas em condomínios de classe média alta/alta). (Participante 15)

O mais triste é a falta de educação financeira, pois numa situação como essa, a maioria dos músicos que eu conheço, músicos que ganhavam muito bem, estão passando sérias necessidades financeiras, pois sempre gastaram tudo o que ganhavam. (Participante 17)

A partir dos depoimentos acima, é possível compreender a situação que enfrentaram, principalmente a falta de trabalho, de onde provém o sustento do dia a dia e o que dá dignidade e estabilidade de vida aos músicos. Ainda temos a noção de que quem faz arte não precisa se alimentar, pagar as contas e ter momentos de lazer.

De um cotidiano alegre, divertido e estressante para um cotidiano de tristeza, de angústias e de solidão. Foram momentos de aprendizagens, mas também de dor pelas perdas de amigos, parentes e de trabalho. 


\section{Considerações finais}

O trabalho do artista não é somente na sua apresentação regrada de luzes, sons e movimentos, é um trabalho que exige esforço individual e coletivo. Por trás de todo esse momento, que ele proporciona a quem o prestigia, tem estudo e investimentos.

A desvalorização dos profissionais da música ainda é uma prática cultural instalada em todo o Brasil. No período do Decreto, ficou mais nítida esta situação, praticamente ficaram sem assistência e sem apoio do governo e poucos foram os empresários que se reorganizaram para ajudar o artista.

Ficou mais evidente as diferenças de um músico autônomo para um músico que possui um contrato. Aqueles que atuavam em orquestra continuaram a receber seus salários mensais, mesmo assim, não foi o suficiente para suprir os gastos que já estavam estabelecidos mensalmente.

O músico autônomo, aquele que não tem emprego fixo e nem contrato fixo, que somente recebe quando o serviço é apresentado, esse é o que mais se fragilizou durante todo o período do Decreto. Investir em um equipamento para lives ou contratar um profissional na área da produção audiovisual não recompensaria o retorno do valor gasto com o que poderia ganhar de cachê virtual, novamente seu investimento e seu trabalho seriam desvalorizados.

Muitos músicos, assim como muitos artistas, passaram necessidades financeiras. Mesmo diante dessas distâncias sociais e culturais no próprio grupo social, a solidariedade entre os músicos ajudou alguns que estavam passando necessidades a ter a compra do mês para se alimentar e pagar as contas mensais essenciais.

Pensar a cada dia como será o próximo dia ou o próximo mês, quando tudo isso irá terminar para voltar ao "normal", é angustiante. Diante de um caos vem as tristezas, as frustrações, as doenças, do estresse à ansiedade, do medo à depressão, e o músico não conseguiu fugir dessas sensações e sentimentos.

Vai ficar registrado, na memória individual e coletiva, todo este cenário cruel que se instalou no mundo em função da pandemia da COVID-19. A história vai narrar a vida e a realidade desse tempo que presenciamos, de um tempo em que a arte teve que buscar na sua própria essência esperança para sobreviver e esperança para cantar. 
Diário: Hoje, 07 de janeiro de 2021, Manaus novamente está em lockdown por 15 dias, sob o Decreto Estadual No 43.236 de 28/12/2020, após determinação da justiça, somente funcionando supermercados e drogarias e outros poucos serviços. Além do Decreto Municipal No 5001 DE 04/01/2021 que instituiu estado de emergência no período de 180 (cento e oitenta) dias, em razão da pandemia causada pelo novo Coronavírus (COVID-19). Não estamos mais na fase vermelha, mas na fase roxa ou preta, em um dos piores momentos vivenciados desde abril e maio de 2020: mortes e contágios. Nas redes sociais muitas despedidas virtuais de artistas, familiares e pessoas públicas. Um cenário desolador em que choramos por uma vida que alguém amava, por uma vida que tinha família, sonhos e esperança. É uma questão de saúde e consciência coletiva! Meus sentimentos a todos!

\section{Referências}

AMAZONAS. Decreto estadual $\mathrm{n}^{\circ} 42.330$, de 28 de maio de 2020. Dispõe sobre medidas para enfrentamento da emergência de saúde pública de importância internacional, decorrente do novo coronavírus. D. O. E., nº 34.257, Poder Executivo, Seção I, p. 4-6, 28 maio 2020 a.

AMAZONAS. Decreto estadual no 43.236, de 28 de dezembro de 2020. Estabelece novas medidas para enfrentamento da emergência de saúde pública de importância internacional, decorrente do novo coronavírus. D. O. E., n 34.400, Poder Executivo, Seção I, p.1-4, 28 dez. 2020 b.

BOURDIEU, Pierre. As regras da arte: gênese e estrutura do campo literário. Tradução Maria Lucia Machado. São Paulo: Companhia das Letras, 1996.

CASA NOVA, Silvia Pereira de Castro (org.). Trabalho de conclusão de curso (TCC): uma abordagem leve, divertida e prática. São Paulo: Saraiva, 2020.

CERTEAU, Michel de. A invenção do cotidiano: artes de fazer. Tradução Ephraim Ferreira Alves. Petrópolis: Vozes, 1994. v. 1.

FREIRE, Vanda Lima Bellard. Pesquisa em música: novas abordagens. Belo Horizonte: Escola de Música da UFMG, 2007.

FUBINI, Enrico. Estética da música. Tradução Sandra Escobar. Lisboa: Biblioteca Nacional de Portugal/ Edições 70, 2003.

GOHN, Daniel Marcondes. Educação musical a distância: abordagens e experiências. São Paulo: Cortez, 2011.

GOHN, Daniel Marcondes. A segunda fase da vivência tecnológica. In: SANTIAGO, Glauber (org.). Uso de recursos tecnológicos no ensino musical. São Carlos: EdUFSCar, 2017, p. 23-36.

GONÇALVES, Renato. A valorização da música e a desvalorização do músico: a pandemia do COVID19 expõe a vulnerabilidade do trabalho musical pós-digital. Rev. Bravo. 23 mar. 2020. Disponível em: https://medium.com/revista-bravo/a-valoriza\%C3\%A7\%C3\%A3o-da-m\%C3\%BAsica-e-adesvaloriza\%C3\%A7\%C3\%A3o-do-m\%C3\%BAsico-c5d409008fd3. Acesso em: 26 dez. 2020.

HELLER, Agnes. O cotidiano e a história. Tradução: Carlos Nelson Coutinho e Leandro Konder. 11 ed. São Paulo: Paz e Terra, 2016.

LE GOFF, Jacques. História e memória. 7.ed. rev. Campinas: Editora da Unicamp, 2013. 
LOURO, Viviane; LOURO, Fabiana dos Santos; DUARTE, Plinio Gladstone. O estresse gerado pela pandemia como risco para adoecimento mental e físico do músico a partir das neurociências cognitivas. Revista Música, v. 20, n. 2, p. 379-96, 2020. Disponível em: https://www.revistas.usp.br/revistamusica/article/view/178817/167000. Acesso em: 15 jan. 2020.

MANAUS (AM). Decreto municipal $\mathrm{n}^{\circ}$ 5.001, de 04 de janeiro de 2021. Estabelece novas medidas para enfrentamento da emergência de saúde pública de importância internacional, decorrente do novo coronavírus. D. O. M., ed. 5000, p. 2-3, 04 jan. 2021.

PESAVENTO, Sandra Jatahy. História e história cultural. 2.ed. Belo Horizonte: Autêntica, 2008.

PINA, Isabella. Após pico em maio, Amazonas tem duas semanas seguidas de queda em casos de COVID-19 [...] G1 Amazonas, 20 jun. 2020. Disponível em: https://g1.globo.com/am/amazonas/noticia/2020/06/20/apos-pico-em-maio-amazonas-tem-duassemanas-seguidas-de-queda-em-casos-de-COVID-19-e-reducao-chega-a-38percent-aponta-fvs.ghtml. Acesso em: 11 abr. 2021.

SILVA, Ricardo. $86 \%$ dos profissionais da música tiveram perdas na pandemia. 2020. Disponível em: http://www.ubc.org.br/Publicacoes/Noticias/16842. Acesso em: 26 dez. 2020.

WORLD HEALTH ORGANIZATION. Coronavirus disease (COVID-19) pandemic. c2021a. Disponível em: https://www.who.int/emergencies/diseases/novel-coronavirus-2019. Acesso em: 11 abr. 2021.

WORLD HEALTH ORGANIZATION. WHO announces COVID-19 outbreak a pandemic. c2021b. Disponível em: https://www.euro.who.int/en/health-topics/health-emergencies/coronavirus-COVID19/news/news/2020/3/who-announces-COVID-19-outbreak-a-pandemic. Acesso em: 11 abr. 2021. 